Emerg Infect Dis. 2009;15:985-7. http://dx.doi.org/10.3201/ eid1506.080232

10. Almuzara MN, Palombarani S, Tuduri A, Figueroa S, Gianecini A, Sabater L, et al. First case of fulminant sepsis due to

Wohlfahrtiimonas chitiniclastica. J Clin Microbiol. 2011;49:23335. http://dx.doi.org/10.1128/JCM.00001-11

Address for correspondence: Yuichi Katanami, National Center for Global Health and Medicine, Disease Control and Prevention Center, 1-21-1, Toyama, Shinjuku, Tokyo 162-8655, Japan; email: yuichi.katanami@gmail.com

\section{Symptomatic Dengue during Pregnancy and Congenital Neurologic Malformations}

\author{
Enny S. Paixão, Maria Glória Teixeira, \\ Maria da Conceição N. Costa, \\ Mauricio L. Barreto, Laura C. Rodrigues
}

\begin{abstract}
Author affiliations: London School of Hygiene and Tropical Medicine, London, United Kingdom (E.S. Paixão, L.C. Rodrigues); Instituto de Saúde Coletiva, Salvador-Bahia, Brazil (E.S. Paixão, M.G. Teixeira, M. da Conceição N. Costa, M.L. Barreto); Center of Data and Knowledge Integration for Health (CIDACS), Salvador-Bahia (M.L. Barreto, L.C. Rodrigues)
\end{abstract}

DOI: https://doi.org/10.3201/eid2409.170361

Dengue virus infection during pregnancy increased the risk for any neurologic congenital anomaly in the infant by roughly $50 \%$ and for other congenital malformations of brain 4-fold. Our results show an association between dengue during pregnancy and congenital anomalies of the brain, suggesting that flaviviruses other than Zika virus are associated with such malformations.

$\mathrm{B}$ efore the causal relationship between Zika virus and neurologic congenital anomalies (1), especially microcephaly (2), was established, no evidence associated flavivirus with congenital malformations in humans, although postnatal complications have been described (3). We investigated whether dengue virus (DENV) infection during pregnancy could be associated with neurologic defects in the infant at birth.

We conducted a population-based study using routinely collected data from live births and from women who were notified and confirmed to have DENV infection during 2006-2012 in Brazil, before the introduction of Zika virus. We probabilistically linked records of mothers of live births with records of dengue notification to identify women who were reported as having dengue during pregnancy. We excluded records with missing or implausible names, multiple pregnancies, and births in municipalities with no dengue notifications. We obtained ethics approval from Federal University of Bahia, Salvador, Brazil (CAAE: 26797814.7.0000.5030) and from London School of Hygiene and Tropical Medicine (Ethics Ref:10269).

In the matching process, we used name, age, and place of residence of the mother at time of delivery and notification. We included only links and nonlinks with a high degree of certainty. We validated the linkage process in a study that demonstrated $62 \%$ sensitivity (4).

We used an outcome definition of congenital malformation of the nervous system coded as Q00-Q07 in International Classification of Diseases, 10th Revision (ICD-10). We defined dengue as a confirmed case of DENV infection notified during a pregnancy that resulted in a live birth. We estimated the association between symptomatic dengue during pregnancy and neurologic congenital malformations using the Firth method to reduce the small sample bias in maximum-likelihood estimation.

The study parameters encompassed 16,103,312 live births. Neurologic congenital anomalies are rare; they occurred in 13,634 (0.08\%) live births. Dengue during pregnancy increased the odds of a neurologic congenital anomaly by $50 \%$ (Table), but this result was not statistically significant (95\% CI $0.97-2.27)$. We split the neurologic congenital defects into ICD-10 categories; the 95\% $\mathrm{CI}$ around the estimated odds ratios (ORs) was not statistically significant in 7 categories, including microcephaly (OR 1.7, 95\% CI 0.33-8.32). Two other types of neurologic congenital anomalies were $>4$ times more frequent in women who had DENV infection during pregnancy: other congenital malformations of spinal cord (OR 5.4, 95\% CI 1.0-26.9) and other congenital malformations of brain (OR 4.5, 95\% CI 1.7-11.3, which was statistically significant). We found no sign of space-time clusters or recording errors suggestive of a coding artifact in the 4 records of other congenital malformations of brain wherein the mother had DENV infection (online Technical Appendix Table, https://wwwnc.cdc.gov/EID/article/24/9/17-0361Techapp1.pdf)

Symptoms of DENV infection occurred in the first trimester in $50 \%$ of patients. The specific diagnosis of those among the nonexposed group were congenital malformation of corpus callosum $(9 \% ; 81 / 943)$, holoprosencephaly $(24 \% ; 225 / 943)$, and septooptic dysplasia $(0.6 \% ; 6 / 943)$.

Our study showed an association between DENV infection during pregnancy and congenital anomalies of the 
Table. Association between congenital anomalies and symptomatic dengue virus infection during pregnancy, Brazil, 2006-2012

\begin{tabular}{lc}
\hline Congenital anomaly & Odds ratio $(95 \% \mathrm{Cl})$ \\
\hline Neurologic congenital anomalies & $1.5(0.9-2.2)$ \\
Anencephaly & $1.9(0.8-4.4)$ \\
Encephalocele & $1.4(0.3-6.9)$ \\
Microcephaly & $1.7(0.3-8.3)$ \\
Congenital hydrocephalus & $1.6(0.8-3.2)$ \\
Other congenital malformations of & $4.5(1.7-11.3$ \\
brain & 0.8 \\
Spina bifida & 5.4 \\
Other congenital malformations of & \\
spinal cord & Not available \\
Other congenital malformations of & \\
nervous system & \\
\hline
\end{tabular}

brain. Congenital anomalies of the brain detectable by routine examination at birth are so rare $(6 / 100,000$ live births by our data) that it was necessary to assemble a cohort of $>16$ million live births to detect an effect of dengue; even then, we did not have sufficient power to confidently exclude associations with other neurologic abnormalities.

Because DENV infection had not been associated with congenital anomalies, there is no established biologic mechanism for its teratogenicity. However, there is evidence for postnatal neurotropism and virus isolation from brain tissue (5) and for dengue virus crossing the bloodbrain and placental barriers $(6,7)$. The pattern of anomalies we described has similarities with congenital Zika syndrome. Brain images and autopsies from infants with Zika and other infectious diseases have revealed abnormalities similar to those we described $(8,9)$.

Our study has limitations inherent to the linkage process. Rigorous evaluation of the linkage process showed that it is unlikely to introduce bias and that it did not affect the magnitude of the association (4). Another potential limitation was diagnosis of DENV infection. In notifiable epidemics, not all cases are tested after the cause is established. DENV infection in Brazil is notified for the presence of clinical criteria, laboratory confirmation, or both. Only $\approx 30 \%$ of notified DENV infections are laboratory confirmed, which could lead to bias if unconfirmed cases are not dengue. However, a previous article found no difference in pregnancy outcomes for women with notified DENV infection with and without laboratory confirmation (10). We did not control for potential confounders, so confounders such as maternal illness or environmental exposures may have contributed to the association between dengue infection and neurologic malformations.

The association of symptomatic dengue during pregnancy and congenital anomalies of the brain in the infant, while not as high frequency as the linkage with Zika, opens the possibility of other flaviviruses causing congenital malformations and raises questions about policy implications. We recommend careful observation and recording of
DENV infection in antenatal records and full investigation of live births with neurologic malformations, as well as animal and in vitro research of teratogenic effects of dengue.

E.S.P. is funded by the National Council of Technological and Scientific Development (CNPq), Brazil, and L.C.R. is partially funded by the European Union's Horizon 2020 research and innovation program under Zika-PLAN grant agreement No. 734584. The funders of this study had no role in study design, data collection, data analysis, data interpretation, or writing of the report.

Authors' contributions: E.S.P. carried out the analysis and wrote the first draft of the article. L.C.R. and M.G.T. conceived the study. M.da C.N.C. and M.L.B. contributed to the study design and interpretation. All authors revised the manuscript and approved the final version.

\section{About the Author}

Ms. Paixão is a PhD student at London School of Hygiene and Tropical Medicine. Her main research interests are congenital infections and use of routinely collected data.

\section{References}

1. Rasmussen SA, Jamieson DJ, Honein MA, Petersen LR. Zika virus and birth defects - reviewing the evidence for causality. N Engl J Med. 2016;374:1981-7. http://dx.doi.org/10.1056/NEJMsr1604338

2. de Araújo TVB, Rodrigues LC, de Alencar Ximenes RA, de Barros Miranda-Filho D, Montarroyos UR, de Melo APL, et al.; investigators from the Microcephaly Epidemic Research Group; Brazilian Ministry of Health; Pan American Health Organization; Instituto de Medicina Integral Professor Fernando Figueira; State Health Department of Pernambuco. Association between Zika virus infection and microcephaly in Brazil, January to May, 2016: preliminary report of a case-control study. Lancet Infect Dis. 2016;16:1356-63. http://dx.doi.org/10.1016/ S1473-3099(16)30318-8

3. John CC, Carabin H, Montano SM, Bangirana P, Zunt JR, Peterson PK. Global research priorities for infections that affect the nervous system. Nature. 2015;527:S178-86. http://dx.doi.org/ 10.1038/nature16033

4. Paixão, ES, Harron K, Andrade K, Teixeira MG, Fiaccone RL, Costa MDCN, et al. Evaluation of record linkage of two large administrative databases in a middle income country: stillbirths and notifications of dengue during pregnancy in Brazil. BMC Med Inform Decis Mak. 2017;17:108.

5. Carod-Artal FJ, Wichmann O, Farrar J, Gascón J. Neurological complications of dengue virus infection. Lancet Neurol. 2013; 12:906-19. http://dx.doi.org/10.1016/S1474-4422(13)70150-9

6. Chaturvedi UC, Dhawan R, Khanna M, Mathur A. Breakdown of the blood-brain barrier during dengue virus infection of mice. J Gen Virol. 1991;72:859-66. http://dx.doi.org/10.1099/ 0022-1317-72-4-859

7. Castanha PMS, Braga C, Cordeiro MT, Souza AI, Silva CD Jr, Martelli CM, et al. Placental transfer of dengue virus (DENV)specific antibodies and kinetics of DENV infection-enhancing activity in Brazilian infants. J Infect Dis. 2016;214:265-72. http://dx.doi.org/10.1093/infdis/jiw143

8. Martines RB, Bhatnagar J, de Oliveira Ramos AM, Davi HP, Iglezias SD, Kanamura CT, et al. Pathology of congenital Zika 
syndrome in Brazil: a case series. Lancet. 2016;388:898-904. http://dx.doi.org/10.1016/S0140-6736(16)30883-2

9. Nunes ML, Carlini CR, Marinowic D, Neto FK, Fiori HH, Scotta MC, et al. Microcephaly and Zika virus: a clinical and epidemiological analysis of the current outbreak in Brazil. J Pediatr (Rio J). 2016;92:230-40. http://dx.doi.org/10.1016/ j.jped.2016.02.009

10. Paixão ES, Costa MDCN, Teixeira MG, Harron K, de Almeida MF, Barreto ML, et al. Symptomatic dengue infection during pregnancy and the risk of stillbirth in Brazil, 2006-12: a matched case-control study. Lancet Infect Dis. 2017;17:957-64. http://dx.doi.org/10.1016/S1473-3099(17)30366-3

Address for correspondence: Enny S. Paixão, London School of Hygiene and Tropical Medicine, Keppel St, London WC1E 7HT, UK; email: enny.cruz@1shtm.ac.uk

\section{Travelers' Actual and Subjective Knowledge about Risk for Ebola Virus Disease}

\author{
Isabelle Régner, Oana Elena lanos, \\ Loucy Shajrawi, Philippe Brouqui, \\ Philippe Gautret
}

\begin{abstract}
Author affiliation: Aix-Marseille Université, Marseille, France
(I. Régner); Méditerranée Infection Institute, Marseille (O.E. Ianos,

L. Shajrawi, P. Brouqui, P. Gautret)
\end{abstract}

DOI: https://doi.org/10.3201/eid2409.171343

To determine travelers' actual and subjective knowledge about risk for Ebola virus disease, we surveyed travelers from France. Actual knowledge did not prevent irrational perceptions or promote safe behavior. Rather, readiness to adopt protective behavior depended on subjective knowledge and overconfidence in ability to self-protect.

$\mathrm{T}$ he 2014-2016 epidemic of Ebola virus disease (EVD) in West Africa was the largest ever recorded. As for many other infectious diseases $(1,2)$, surveys of knowledge, attitudes, and practices report suboptimal knowledge and misperceptions of risk for EVD among various populations (3-6). Recommendations typically emphasize the need to increase actual knowledge (what persons really know) to reduce irrational beliefs and risky behavior. However, subjective knowledge (what persons think they know), which has been overlooked in EVD surveys, can lead to the erroneous feeling that one has the requisite knowledge to avoid adverse events, resulting in a higher risk of experiencing negative outcomes (7). To determine if actual and subjective knowledge about EVD would lead to differing perceptions of risk, we surveyed travelers from France who had visited the International Vaccination Center at North Hospital in Marseille, France, for pretravel consultation during May 2015-February 2016.

A sample of 189 participants (93 women, 96 men; mean age \pm SD $37.78 \pm 14.50$ years) anonymously completed a questionnaire about their knowledge and perceptions of risk of acquiring EVD. Respondents reported their sociodemographic characteristics, destination, purpose of travel, date of departure, and date of return. Questions about EVD actual knowledge included preventive measures, transmission routes, epidemic status, affected countries, and presence of EVD in the destination country. We used correct responses to compute final scores (online Technical Appendix, https:// wwwnc.cdc.gov/EID/article/24/9/17-1343-Techapp1.pdf). We used 5-point Likert scales $(1=$ strongly disagree to $5=$ strongly agree) to record travelers' self-reports pertaining to their subjective knowledge (7) and several risk perceptions about $\operatorname{EVD}(6,8,9)$ : perceived seriousness of EVD, awareness of EVD risk in the destination country, perceived effectiveness of protective measures, fear of contracting EVD in the country of destination, fear of contracting EVD in Europe, and intentions to adopt preventive behavior. Personal control and unrealistic optimism were assessed as key measures of positive illusions that typically lead persons to overestimate their capabilities to protect themselves against adverse events $(8,9)$ (online Technical Appendix).

Among the 189 participants, $25.9 \%$ planned to travel to West Africa (2.6\% to an affected country, Guinea), 21.7\% to other African countries, and $52.4 \%$ to other countries worldwide. Only $10.6 \%$ were able to correctly report the 3 countries affected by the EVD epidemic (Liberia, Sierra Leone, Guinea), and many were unaware of preventive measures (45\%) and modes of Ebola virus transmission (39.1\%). The most frequent answers for preventive measures were practice careful hygiene (24.34\%), avoid contact with infected persons (23.28\%), and wear protective equipment $(21.16 \%)$. Answers about modes of Ebola virus transmission were body contact (31.22\%), body fluids (30.16\%), and aerosol (12.17\%; this answer is wrong). Overall, the actual knowledge about EVD was very low (mean 3.57 correct responses; maximum possible score $=16$ ). Simultaneously, subjective knowledge was low (mean \pm SD 2.39 \pm 1.00 ; maximum possible score $=5.00$ ) (online Technical Appendix Table 3 for bivariate intercorrelations).

To go beyond bivariate correlations and to estimate the associations between risk perceptions and each type of knowledge, we used multiple regression analyses (Table). Findings showed that actual knowledge was far from being as effective, as typically thought from knowledge, 